\title{
Counter-current immunoelectrophoresis for the diagnosis of pneumococcal chest infection
}

\author{
M. EL-REFAIE AND C. DULAKE
}

From the Public Health Laboratory, Dulwich Hospital, East Dulwich Grove, London SE22

SYNOPSIS Counter-current immunoelectrophoresis is a rapid sensitive method for detecting pneumococcal capsular antigens in sputum. A result can be obtained within 45 minutes. The optimum conditions for performing the test are given. Counter-current immunoelectrophoresis works with all the 33 pneumococcal antigens tested except type 14. Better precipitin lines are obtained when the gel-support is acid ( $\mathrm{pH} \mathrm{6.6)}$ than when it is alkaline (pH 8.6). Omniserum is as effective as group-specific sera for the identification of pneumococcal capsular antigens. The findings suggest that pneumococcal infection was present in $44 \%$ of 300 unselected suspected chest infections. Culture for pneumococci was positive in only $15 \%$ of these cases. The clinical importance of these findings is still being studied but our experience has shown that patients with chest infections should have effective antipneumococcal antibiotics as part of their regimen and that the laboratory diagnosis may be made quickly and accurately by counter-current immunoelectrophoresis.

The diagnosis of pneumococcal chest infection is usually done by the bacteriological examination of sputum (Gram stain and culture). For many years it has been known that the sputum may be contaminated by the bacterial flora of the mouth and pharynx (Mulder, 1938), and that pneumococci in the sputum may be indicative of lower respiratory tract infection or just derived from the throat (Brumfitt et al, 1957; Lees and McNaught, 1959). Because infected lower respiratory tract secretions were found to contain very large numbers of potential pathogens (Laurenzi et al, 1961; Cooper et al, 1961), quantitative cultural techniques of the sputum have been suggested (Louria, 1962), and culture of a suitable dilution of liquefied sputum ( 1 in 10000$)$ has been recommended as a routine procedure in sputum examination (Dixon and Miller, 1965). However, these methods do not necessarily identify the cause of lung infection (Hahn and Beaty, 1970; Johanson et al, 1972) and, moreover, fail to differentiate between infected and contaminated sputa (Percival and Roberts, 1972).

Previous antimicrobial therapy is a major problem in the diagnosis of bacterial chest infections other than pulmonary tuberculosis. Crofton (1970) writes, 'Even a single dose of antimicrobial agent before admission may suppress growth, particularly of pneumococci'. Spencer and Philp (1973) showed that previous antibiotic treatment seriously distorted the

Received for publication 7 April 1975. bacteriological findings in pneumonia, and Percival (1973) observed that it was hard to judge the clinical relevance of the laboratory findings.

An ideal technique for the identification of bacterial pathogens other than tubercle bacilli in chest infections is highly desirable and should distinguish between infected and contaminated sputa and overcome the difficulty of previous antibiotic therapy. Counter-current immunoelectrophoresis has been used for the detection of microbial antigens in body fluid (Edwards, 1971; Dorff et al, 1971), and this method has been applied to sputum (Tugwell and Greenwood, 1974; Verhoef and Jones, 1974; Spencer and Savage, 1974). It overcomes the difficulty of previous antibiotic therapy (Tugwell and Greenwood, 1975) and has the additional advantage that the results are available within an hour of the specimens being received. In this study we have adapted counter-current immunoelectrophoresis so that it is more sensitive for the detection of pneumococcal capsular antigen in the sputum of patients with a wide variety of chest infections.

\section{Materials and Methods}

ANTISERA

Rabbit anticapsular antisera were obtained from the Statens Serum Institute, Copenhagen, Denmark, as (1) concentrated serum, an 'Omni-serum', giving capsular reaction with all 82 pneumococcal types, 
(2) nine group-specific sera, called by the letters A to I, together reacting with all types (Lund, 1963), and (3) 46 monovalent sera, numbered 1 to 48 (numbers 26 and 30 are not used since these types were later found to belong serologically to groups 6 and 15 respectively) (Lund, 1970). Sera were stored at $4^{\circ} \mathrm{C}$ until used.

\section{ANTIGENS}

For the development of counter-current immunoelectrophoresis and for determining the potency of the antigen-detecting system (Danish antipneumococcal sera) pneumococcal capsular antigens were prepared from pneumococcal strains which were isolated from pathological materials in the laboratories of various hospitals in London. Five single colonies of pneumococci were grown in $10 \mathrm{ml}$ of serum broth overnight at $37^{\circ} \mathrm{C}$. If the pneumococcus was type 3 , one loopful of the coalesced mucoid colonies was taken. The resulting growth (heavy, homogeneous, and bile-soluble) was typed using the group- and type-specific sera by the 'Quellung' reaction. Mixed pneumococcal growth was discarded. Extraction of pneumococcal antigen was carried out by a simple process of deproteinization (boiling and centrifugation) followed by precipitation with acetone and redissolving the precipitate in $5 \mathrm{ml}$ of distilled water ( $\mathrm{pH} \mathrm{7.0)}$. The extracted antigens were kept deep frozen $\left(-20^{\circ} \mathrm{C}\right)$. Thirty-three types were prepared and counter-current immunoelectrophoresis was applied using the Danish antisera. Thirty-three antigens of the same types were also prepared from antigen-positive sputum samples of patients with chest infections, using the same procedure. Before deproteinization, sputa were mixed thoroughly with an equal volume of 'Sputolysin' 1 - a mucolytic agent - and kept at $4{ }^{\circ} \mathrm{C}$ for one to two weeks. Diluted pneumococcal antigens were used for testing the sensitivity of the antisera.

\section{COUNTER - CURRENT}

\section{IMMUNOELECTROPHORESIS}

Glass slides $(8 \times 8 \mathrm{~cm})$ were coated with $1 \%$ agarose in veronal-acetate buffer $(0.092 \%$ barbituric acid, $1.031 \%$ sodium barbital, and $0.68 \%$ sodium acetate at $\mathrm{pH} 8.6$ and ionic strength 0.05 ). The slide was coated with $10 \mathrm{ml}$ of agarose giving thickness of a little more than $1 \mathrm{~mm}$. A 54 well-pattern, consisting of three parallel columns of nine paired wells each, was cut through a plastic template of our design. The columns were $11 \mathrm{~mm}$ apart. Wells were $3 \mathrm{~mm}$ in diameter and the inter-well spaces in each column were $2 \mathrm{~mm}$. The pattern was displaced toward the anode, leaving a $2 \mathrm{~cm}$ margin at the cathodic edge

\footnotetext{
${ }^{1}$ Sputolysin is a product of Calbiochem, California, USA
}

of the slide. The antibody wells were on the anodic side of the pattern. Two microlitres of antigen or antibody were added to the respective well with a microsyringe. Counter-current immunoelectrophoresis was carried out at room temperature with a Shandon Vokam power pack for 30-45 minutes using a constant current of $30 \mathrm{~mA}$ per slide $(2.6$ volts $/ \mathrm{cm}$ ) and full strength buffer in the electrophoretic vessel. The method is a discontinuous system.

\section{GEL-IMMUNODIFFUSION}

Gel-immunodiffusion was also done with the plate micro-Ouchterlony technique using the same support as in counter-current immunoelectrophoresis. $\infty$ Approximately five to 10 times as much antigen and $\vec{\circ}$ antibody were used with gel diffusion as with electrophoresis. Pneumococcal antigens were tested against homologous monovalent sera.

\section{STUDY -SAMPLES}

Three hundred consecutive sputum samples $(55 \%$ purulent, $35 \%$ mucopurulent, and $10 \%$ mucoid) from patients with chest infections at Dulwich Hospital, over a two-month period (Octobers November 1974), were tested. More than $80 \%$ \& the patients had had antibiotic therapy before samples were taken. Testing and culture were carrief out simultaneously on the day the samples were received. Sputum was homogenized with an equal volume of Sputolysin (a sterile concentrated solution of Cleland's reagent dithiothreitol in a physiological buffer at $\mathrm{pH}$ 7.0). Counter-current immunoelectrophoresis was applied to the homogenate at a dilution of $1: 2$. Further dilution of the sputum was not required. Three samples were run per slide using group-specific sera. Fifty-four sputa, kept at $4^{\circ} \mathrm{C}$, were re-tested using Omniserum.

For culture, a semiquantitative technique was performed. One standard loopful $(\mathrm{SL}=0.01 \mathrm{ml})$ of the homogenate was plated directly on a horse blood agar plate; another SL was thoroughly mixed with $10 \mathrm{ml}$ of peptone water, and from this one SL was plated on half a chocolate agar plate. After overnight incubation at $37^{\circ} \mathrm{C}$, colonies growing on $\mathrm{N}$ the chocolate plates which indicated significant pneumococcal growth (1-5 colonies $=10^{5}-10^{6}$ of pneumococci per ml sputum) were identified and typed. Similarly, colonies of pneumococci on blood agar plates were identified and typed.

\section{CONTROLS}

Negative controls consisted of (1) Sputolysin, (2) serum broth, (3) serum broth cultures of associated isolates (Streptococcus viridans, Haemophilus species, coliform bacilli, etc) occurring with pneumococci 
on cultural plates and with positive counter-current immunoelectrophoresis, (4) extracts of serum broth cultures of these organisms made following the same procedure as in the preparation of pneumococcal antigens, and (5) 100 tuberculous sputum samples. Counter-current immunoelectrophoresis was applied to all controls using Omniserum and groupspecific sera; in the case of associated isolates, typespecific serum was also used.

\section{Results}

The sensitivity of counter-current immunoelectrophoresis for detection of pneumococcal capsular antigen was found to be subject to many variables.
The effect of the type of gel-support is shown in table I. Optimum results were obtained with agarose dissolved in veronal buffer at $\mathrm{pH} \mathrm{6.6}$. Three advantages were gained by an acidic $\mathrm{pH}:(1)$ precipitin lines were nearly midway between the wells; (2) there was a decrease in the anodal electroendosmotic flow; and (3) there was a $1 \frac{1}{2}$ to 2 -fold increase in the sensitivity as compared with the same support at pH 8.6.

Table II shows the effect of the type of wellpattern. The sensitivity was decreased with well sizes less than $3 \mathrm{~mm}$, spaces between antigen and antibody wells (edge to edge) greater than $2 \mathrm{~mm}$, and wells of irregular shape. The position of the wells on the slide hardly affected the sensitivity. Positive reactions were developed within 10-20

\begin{tabular}{|c|c|c|c|c|c|c|c|c|c|c|c|}
\hline \multirow[t]{3}{*}{ Gel-support $^{1}$} & \multicolumn{4}{|c|}{ Result in minute-time } & \multicolumn{3}{|c|}{ Characters of Precipitin Lines ${ }^{2}$} & \multirow{3}{*}{$\begin{array}{l}\text { Anodal } \\
\text { Endosmotic } \\
\text { Flow of Serum }\end{array}$} & \multirow{2}{*}{\multicolumn{3}{|c|}{$\frac{\text { Sensitivity }^{2}}{\text { PCA tested }}$}} \\
\hline & \multirow[t]{2}{*}{10} & \multirow[t]{2}{*}{20} & \multirow[t]{2}{*}{30} & \multirow[t]{2}{*}{45} & \multirow[t]{2}{*}{ Site } & \multirow[t]{2}{*}{ Shape } & \multirow[t]{2}{*}{ Intensity } & & & & \\
\hline & & & & & & & & & $\begin{array}{l}\text { Type } \\
25\end{array}$ & $\begin{array}{l}\text { Type } \\
31\end{array}$ & $\begin{array}{l}\text { Type } \\
35\end{array}$ \\
\hline \multicolumn{12}{|l|}{ In veronal buffer pH 8.6: } \\
\hline $\begin{array}{l}\text { Agarose } \\
\text { Agarose }+ \text { Nobel agar }(1 \cdot 1)\end{array}$ & + & + & + & + & $\mathbf{A}+++$ & $\mathbf{R}$ & $\mathbf{G}$ & $2+$ & 500 & 2000 & 2000 \\
\hline Agarose + Nobel agar $(1: 1)$ & - & + & + & + & & $\mathbf{S}$ & G & $1+$ & 250 & 500 & 500 \\
\hline Bacto-agar (Difco) & + & + & + & + & $\mathbf{T}+$ & $\mathbf{S}$ & G & $\frac{1}{2}+$ & 250 & 1000 & 500 \\
\hline Nobel-agar & - & - & + & + & $\mathbf{T}$ & $\mathbf{S}$ & $\mathbf{M}$ & None & 50 & 250 & 250 \\
\hline \multicolumn{12}{|l|}{ Agarose in: } \\
\hline Veronal buffer pH 8.2 & + & + & + & + & $\mathbf{A}+++$ & $\mathbf{R}$ & G & $2+$ & 500 & 2500 & 2500 \\
\hline pH 7.8 & + & + & + & + & $\mathbf{A}++$ & $\mathbf{R}$ & G & $1+$ & 500 & 2500 & 2500 \\
\hline pH 7.4 & + & + & + & + & $\mathbf{A}+$ & $\mathbf{R}$ & G & $1+$ & 500 & 2500 & 2500 \\
\hline pH 7.0 & + & + & + & + & $\mathbf{A}+$ & $\mathbf{R}$ & G & $1+$ & 500 & 3000 & 3000 \\
\hline pH 6.6 & + & + & + & + & A & $\mathbf{R}$ & G & $1+$ & 1000 & 3000 & 3000 \\
\hline pH 6.2 & + & + & + & + & $\mathbf{A}$ & $\mathbf{R}$ & $\mathbf{G}$ & $1+$ & 500 & 2500 & 2500 \\
\hline pH 5.8 & + & + & + & + & A & $\mathbf{R}$ & $\mathbf{M}$ & $1+$ & 500 & 2500 & 2000 \\
\hline pH 5.4 & + & + & + & + & C & $\mathbf{R}$ & $\mathbf{M}$ & $\frac{1}{2}+$ & 500 & 2000 & 2000 \\
\hline pH 5.0 & + & + & + & + & C & $\mathbf{S}$ & $\mathbf{w}$ & $\frac{1}{2}+$ & 250 & 1000 & 1000 \\
\hline \multirow{3}{*}{$\begin{array}{l}\text { Agarose in: } \\
\text { Veronal buffer pH } 9.6 \\
\text { Tris buffer pH } 9.6\end{array}$} & & & & & & & & & & & \\
\hline & + & + & + & + & $\mathbf{A}+++$ & $\mathbf{R}$ & $\mathbf{M}$ & $2+$ & 250 & 500 & 1000 \\
\hline & - & - & - & - & $\mathbf{A}+++$ & $\mathbf{R}$ & $\mathbf{M}$ & $1+$ & 50 & 100 & 100 \\
\hline
\end{tabular}

Table I Effect of gel-support on CIE for detection of pneumococcal capsular antigens (PCA)

'Veronal buffer (pH 8.6) in electrophoretic vessel, constant current of $30 \mathrm{~mA}$ per slide

'From the edge of the antibody well $A+++=0.2 \mathrm{~mm}, A++=0.4 \mathrm{~mm}, A+=0.6 \mathrm{~mm}, \mathrm{~A}=0.8 \mathrm{~mm} ; \mathrm{C}=$ central; T $=0.2 \mathrm{~mm}$

from antigen well; $T+=$ on antigen well; $R=\operatorname{arc} ; \mathbf{S}=$ straight; $\mathbf{G}=$ good; $\mathbf{M}=$ moderate; $W=$ weak

${ }^{3}$ Figures indicate the reciprocal of maximum dilution of PCA detected using undiluted homologous monovalent serum

\begin{tabular}{|c|c|c|c|c|c|c|}
\hline \multirow[t]{3}{*}{ Gel-support ${ }^{1}$} & \multicolumn{2}{|l|}{ Wells } & \multirow[t]{3}{*}{ Site of precipitin lines ${ }^{2}$} & \multirow{2}{*}{\multicolumn{3}{|c|}{$\frac{\text { Sensitivity }^{3}}{\text { PCA tested }}$}} \\
\hline & \multirow[t]{2}{*}{ Size $(\mathrm{mm})$} & \multirow[t]{2}{*}{ Inter-space $(\mathrm{mm})$} & & & & \\
\hline & & & & Type 25 & Type 31 & Type 35 \\
\hline Agarose' in veronal buffer $\mathrm{pH} 8.6$ & $\begin{array}{l}2 \\
3 \\
\text { Irregular } \\
2 \\
2 \\
2 \\
3\end{array}$ & $\begin{array}{l}2 \\
2 \\
2 \\
3 \\
5 \\
5 \\
3\end{array}$ & $\begin{array}{l}\mathbf{A b}(\mathbf{A}+++) \\
\mathbf{A}+++(\mathbf{A}) \\
\mathbf{A}+++(\mathbf{A}) \\
\mathbf{A}++(\mathbf{A}) \\
\mathbf{A}+(\mathbf{A}) \\
\overline{\mathbf{A}}+++(\mathbf{A}+)\end{array}$ & $\begin{array}{l}500(500) \\
500(1000) \\
100(100) \\
500(500) \\
50(100) \\
-v e \\
50(250)\end{array}$ & $\begin{array}{l}1000(1500) \\
2000(3000) \\
500(1000) \\
2000(2000) \\
250(250) \\
-v e \\
1000(1500)\end{array}$ & $\begin{array}{c}1500(1500) \\
2000(3000) \\
500(500) \\
1500(2500) \\
250(500) \\
-v e \\
100(1500)\end{array}$ \\
\hline
\end{tabular}

Table II Effect of well-factor on CIE for detection of pneumococcal capsular antigens (PCA)

${ }^{1}$ Veronal buffer (pH 8.6) in electrophoretic vessel, constant current of $30 \mathrm{mH}$ per slide

${ }^{2}$ From the edge of the antibody well $\mathbf{A}+++=0.2 \mathrm{~mm}, \mathbf{A}++=0.4 \mathrm{~mm}, \mathbf{A}+=0.6 \mathrm{~mm}, \mathbf{A}=0.8 \mathrm{~mm}, \mathrm{Ab}=$ on the edge

${ }^{3}$ Figures indicate the reciprocal of maximum dilution of PCA detected using undiluted homologous monovalent serum

'Figures in parentheses show the effect of using agarose in veronal buffer $\mathrm{pH} 6.6$ 
minutes with a constant current of $30 \mathrm{~mA}$ per slide. No advantage was gained by longer electrophoresis.

The reactivity of Danish antisera is shown in table III. The two sets of pneumococcal antigens prepared had the same reactivity and both gave reactions of complete identity in gel-diffusion. Omniserum was as effective as group-specific sera for the identification of antigens tested. Visible precipitin lines were obtained with Omniserum as well as group-specific sera in all positive sputum samples. Negative results were observed only with type 14 pneumococcal antigen on counter-current immunoelectrophoresis. Attempts were made, by use of different gel-support at different $\mathrm{pH}$, to obtain precipitin lines with this type but all failed. The strains of type 14 pneumococcus tested in this laboratory seem to possess positively charged capsular antigens.

Danish antisera are highly specific for pneumo-

\begin{tabular}{|c|c|c|c|}
\hline \multirow[t]{2}{*}{ Reference $P C A^{1}$} & \multicolumn{3}{|c|}{$\begin{array}{l}\text { Reciprocal of Maximum Dilution of PCA } \\
\text { detected by CIE using Undiluted Serum }\end{array}$} \\
\hline & Omniserum & $\begin{array}{l}\text { Group-specific } \\
\text { Serum }\end{array}$ & $\begin{array}{l}\text { Type-specific } \\
\text { Serum }^{2}\end{array}$ \\
\hline Type 1 & 500 & 500 & $1000(1: 1)$ \\
\hline 3 & 4000 & 4000 & $4000(1: 10)$ \\
\hline 4 & 500 & 500 & $500(1: 1)$ \\
\hline 5 & 2500 & 2500 & $1000(1: 1)$ \\
\hline 6 & 500 & 500 & $500(1: 1)$ \\
\hline 7 & 1000 & 500 & $500(1: 1)$ \\
\hline 8 & 3000 & 3000 & $2500(1: 5)$ \\
\hline 9 & 1000 & 4000 & $4000(1: 10)$ \\
\hline 10 & 2000 & 2000 & $250(1: 1)$ \\
\hline 11 & 2500 & 2500 & 3500 (1:5) \\
\hline 12 & 1000 & 1000 & $1000(1: 5)$ \\
\hline 13 & 1000 & 1000 & $1000(1: 1)$ \\
\hline 14 & Negative $^{3}$ & Negative $^{3}$ & Negative $^{3}(1: 1)$ \\
\hline 15 & 2000 & 2000 & $2500(1: 5)$ \\
\hline 16 & 3500 & 3500 & $3000(1: 10)$ \\
\hline 17 & 2500 & 2500 & $2000(1: 5)$ \\
\hline 18 & 2500 & 2500 & $1000(1: 1)$ \\
\hline 19 & 2500 & 1000 & $1000(1: 5)$ \\
\hline 20 & 2000 & 1000 & $250(1: 1)$ \\
\hline 21 & 250 & 250 & $50(-v e)$ \\
\hline 22 & 2500 & 2500 & $2000(1: 5)$ \\
\hline 23 & 250 & 1000 & $1000(1: 1)$ \\
\hline 24 & 250 & 500 & $250(1: 1)$ \\
\hline 25 & 500 & 500 & $500(1: 1)$ \\
\hline 29 & 1000 & 1000 & $1000(1: 1)$ \\
\hline 31 & 2000 & 2000 & 2000 (1:5) \\
\hline 32 & 3000 & 3000 & $1000(1: 5)$ \\
\hline 33 & 150 & 50 & 50 (-ve) \\
\hline 34 & 1000 & 1000 & $250(1: 1)$ \\
\hline 35 & 2000 & 2000 & $2000(1: 5)$ \\
\hline 36 & 250 & 250 & $250(1: 1)$ \\
\hline 39 & 1000 & 1000 & $250(1: 1)$ \\
\hline 48 & 250 & 250 & $1000(1: 1)$ \\
\hline
\end{tabular}

Table III Sensitivity of 'Danish' antipneumococcal serum in detection of pneumococcal capsular antigens $(P C A)$

${ }^{1}$ Prepared as mentioned (see Methods). Six further types (2, 28, 38 $40,41,47$ ) have been detected but not tested in dilution.

${ }^{2}$ Figures in parentheses show maximum dilution of PCA detected by GID, 1:1 = undiluted PCA.

${ }^{3} \mathrm{CIE}$ does not work with type 14 PCA. coccal capsular antigens. Cross-reaction was observed only once between type 3 pneumococcal $\underline{\underline{0}}$ antigen, detected in a sputum sample, and a strain of Klebsiella isolated from the same sample. This $\stackrel{\vec{F}}{+}$ non-specific reaction was, however, weak and $\mathrm{O}$ required more than 20 minutes to develop, compared with the intense specific reaction observed within 10 minutes. With this one exception, negative results were obtained when associated organisms were tested for the production of cross-reacting antigens.

Table IV summarizes the results of counter- $\vec{\omega}$ current immunoelectrophoresis on 300 consecutive sputum samples and compares these with culture. 용

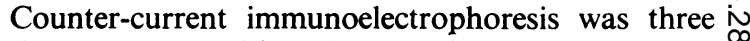
times more sensitive than routine bacteriology in the diagnosis of pneumococcal chest disease; in lobar pneumonia it was sixfold more sensitive than culture. Pneumococcal antigens in sputum of the overall $15 \%$ culture positive cases (except two strains of type 14 pneumococcus) were identical with the strains identified from the chocolate agar plates. The presence of antigen suggests a heavy pneumococcal load in sputum and so implies chest infection. It is of interest that of 100 unselected sputum samples sent for tubercle culture, 38 yielded a few colonies of जे pneumococci on a culture plate from one loopf t্ of sputum but only four had capsular antigens, are these four specimens contained numerous pus cells, suggesting active pneumococcal infection.

Over $90 \%$ of patients whose sputa were antigenpositive by counter-current immunoelectrophoresis were known to have had previous antibiotic treatment. Pneumococcal antigen in the sputum persisted, despite antibiotic therapy, for up to the fifteenth day in three patients with lobar pneumonia and to the fifth day in one patient with bronchitis. No great $?$ difference was observed between the antigen yield $\overline{0}$ of sputa despite the different macroscopic appearance of these specimens.

\begin{tabular}{|c|c|c|c|c|c|}
\hline \multirow[t]{3}{*}{ Clinical Diagnosis } & \multirow{3}{*}{$\begin{array}{l}\text { Number of } \\
\text { Sputum Samples } \\
\text { tested }\end{array}$} & \multicolumn{4}{|c|}{ Positive } \\
\hline & & \multicolumn{2}{|c|}{$C I E$} & \multicolumn{2}{|c|}{ Culture } \\
\hline & & No. & $\%$ & No. & $\%$ \\
\hline $\begin{array}{l}\text { Bronchitis } \\
\text { (acute and acute on chronic) } \\
\text { Pneumonia }\end{array}$ & 85 & 40 & 47 & 16 & 19 \\
\hline Lobar & 18 & 16 & 89 & 3 & 17 \\
\hline Bronchopneumonia & 21 & 8 & 40 & 2 & 10 \\
\hline $\begin{array}{l}\text { Postoperative chest } \\
\text { infection }\end{array}$ & 19 & 8 & 42 & 3 & 16 \\
\hline $\begin{array}{l}\text { Chest infections } \\
\text { (unspecified) }\end{array}$ & 157 & 60 & 38 & 20 & 13 \\
\hline Total & 300 & 132 & 44 & 44 & 15 \\
\hline
\end{tabular}




\section{Discussion}

The greatest difficulties in the bacteriological examination of the sputum arise when an infecting organism may also be part of the normal flora, and when the organism in question may disappear from the sputum after antibiotic treatment. In this study counter-current immunoelectrophoresis, adapted for the rapid detection of pneumococcal antigen, was applied to 300 unselected suspected sputum samples for the purpose of evaluating the efficiency of this technique in diagnosing pneumococcal chest infection. The results (table IV) show that a diagnosis was accomplished in $44 \%$ by counter-current immunoelectrophoresis as opposed to $15 \%$ by culture. It is argued that the presence of pneumococcal antigen in sputum is associated with lower respiratory infection and is not associated with the carrier state. There are several reasons for holding this view.

First, when pneumococci are isolated in significant growth the pneumococcal antigen detected in sputum always matches the type isolated (except type 14). Secondly, lobar pneumonia has the highest antigen rate (16 of 18), a frequency in line with the results of sputum culture of patients with radiologically proved pneumonia who had not received antimicrobial treatment before sputum specimens were taken (Spencer and Philp, 1973). Thirdly, sputa from bronchitis have a relatively lower antigen rate $(47 \%)$ despite the fact that these patients frequently carry pneumococci (Clifton et al, 1955) and that these tend to persist in the respiratory tract despite chemotherapy (Calder and Schonell, 1971). In our experience these patients lose pneumococcal antigen from the sputum within a few days of starting therapy. Fourthly, our findings with 100 unselected sputa sent for tubercle culture show that $\mathbf{3 8}$ yielded a few colonies of pneumococci but only four had capsular antigen, and these four specimens contained numerous pus cells, suggesting active pneumococcal infection.

In lobar pneumonia, counter-current immunoelectrophoresis overcomes the difficulty in diagnosis introduced by previous antimicrobial therapy (Coonrod and Rytel, 1973; Tugwell and Greenwood, 1975). In this study we were frequently able to re-test sputa from four patients with lobar pneumonia. Antigen was found to persist, despite appropriate treatment, up to the fifteenth day in three of these and to the twentyfifth day in the fourth. In bronchitis, however, antigen persisted in most patients to the second or the third day; in one patient only was it detected to the fifth day. The presence of antigen is therefore related to the underlying pathology. Lung tissue with attendant oedema fluid is a more suitable environment for the growth of large numbers of pneumococci and the production of large amounts of antigen.

There are few reports of applying counter-current immunoelectrophoresis on sputum for the purpose of detecting pneumococcal antigen associated with chest infection (Verhoef and Jones, 1974; Spencer and Savage, 1974; Tugwell and Greenwood, 1975) and none of them evaluates the variables of the test or defines the technical conditions necessary for obtaining results of high sensitivity. In the present work we have attempted to adapt counter-current immunoelectrophoresis for the rapid detection of pneumococcal antigen in sputum so that it may be used in routine diagnosis. As may be seen from the results (tables I, II, and III), significant technical points include:

(1) Agarose suspended in veronal buffer at $\mathrm{pH} 6.6$ is an ideal gel-support. Anodal migration of the antigen nearly equals the electroendosmotic flow of the antibody. Diffusion of the serum toward the anode, a disadvantage of agarose, is less with acidic than with alkaline $\mathrm{pH}$. Consequently, a $1 \frac{1}{2}$ to 2 -fold increase in the sensitivity is achieved. The acidic gel suits both low and high titre antigens (also antibodies). Prozones, usually observed with antigen excess on an alkaline support, are not seen on the modified gel except with highly concentrated antigens. Most cases of bronchitis, cases of postoperative chest infection, and some of pneumonia and bronchopneumonia are associated with weak antigen in the sputum. Results showing high sensitivity are observed with these cases by use of the acidic gel.

(2) The $3 \mathrm{~mm}$ well size- $2 \mathrm{~mm}$ inter-well space is a suitable design for pneumococcal antigen/antibody system. Both high and low titre antigens are easily detectable. Most reactions of high titre and antigens are observed within 10 minutes by use of a $30 \mathrm{~mA}$ constant current. Weak antigens need 20 minutes to react. There is no value in longer electrophoresis. The three columns, each of nine paired wells per slide, allow three samples to be tested at the same time, and in as little as 45 minutes a type-specific diagnosis may be reached.

(3) The results of counter-current immunoelectrophoresis depend to a great extent upon the potency and specificity of the antigen-detecting system. In this laboratory Danish antisera react with widely varying concentrations of pneumococcal capsular antigens. Omniserum has the same reactivity as group-specific sera; both are as potent as monovalent serum. All types of sera are highly specific. Except with a strain of Klebsiella, no evidence of cross-reaction was observed in the counter-current immunoelectrophoresis when associated organisms were tested for the production of cross-reacting 
antigens. The specificity of the sera may be affected by longer electrophoresis.

The data presented indicate that 38 pneumococcal capsular antigens may be detected by countercurrent immunoelectrophoresis. More recently, detection of the remaining antigens has been accomplished. An exception is type 14. Similar findings with this type have been observed in the United States (Kenny et al, 1972; Coonrod and Rytel, 1973). It is of interest that type 14 pneumococcus differs in other properties. It is non-pathogenic for mice (MacLeod, 1952) and its capsular polysaccharide is immunologically related to human blood group A substance (Beeson and Goebel, 1939). Epidemiologically, type 14 is one of the most frequent causes of lobar pneumonia in children (Heffron, 1939). In Nigeria, however, it has been reported that type 14 pneumococcal capsular antigen has been satisfactorily detected by counter-current immunoelectrophoresis (Tugwell and Greenwood, 1975). This perhaps reflects differences in the strain between Britain and Nigeria.

We should like to thank Professor A. C. Cunliffe and Mr. C. H. Collins for helpful suggestions, the technical staff of Dulwich Hospital for their assistance and co-operation, and the staff at the laboratories of the London Hospital and St. Olave's Hospital for collecting pneumococcal strains.

This work is supported by a grant from the Egyptian Government.

\section{References}

Beeson, P. B. and Goebel, W. F. (1939). The immunological relationship of capsular polysaccharide of type XIV pneumococcus to the blood group A specific substance. J. exp. Med., 70, 239-247.

Brumfitt, W., Willoughby, M. L. N., and Bromley, L. L. (1957). An evaluation of sputum examination in chronic bronchitis. Lancet, 2, 1306.

Calder, M. A. and Schonell, M. E. (1971). Pneumococcal typing and the problem of endogenous or exogenous re-infection in chronic bronchitis. Lancet, 1, 1156.

Clifton, M., Pownall, M., and Stuart-Harris, C. H. (1955). Observations on the carriage of pneumococci by patients with chronic bronchitis and their families. J. Hyg. (Lond.), 53, 225.

Coonrod, J. D. and Rytel, M. W. (1973). Detection of typespecific pneumococcal antigens by counterimmunoelectrophoresis. J. Lab. clin. Med., 81, 778-786

Cooper, A. W., Williamson, G. M., and Zinneman, K. (1961). Chronic bronchitis changes in the bacterial flora of the sputum associated with exacerbations and long term antibacterial treatment. Brit. J. Dis. Chest., 55, 23.

Crofton, J. (1970). The chemotherapy of bacterial respiratory infections. Amer. Rev. resp. Dis., 101, 841-859.
Dixon, J. M. S. and Miller, D. C. (1965). Value of dilute

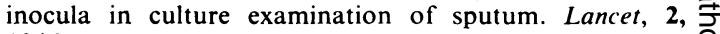
1046.

Dorff, G. J., Coonrod, J. D., and Rytel, M. W. (1971). Detection by immunoelectrophoresis of antigen in sera $\overrightarrow{\bar{F}}$ of patients with pneumococcal bacteraemia. Lancet, 1, 578-579.

Edwards, E. A. (1971). Immunologic investigations of meningococcal disease. 1. Group specific Neisseria meningitidis antigens present in the serum of patients with fulminan meningococcemia. J. Immunol., 106, 314-317.

Hahn, H. H. and Beaty, H. N. (1970). Transtracheal aspıra- ळ) tion in the evaluation of patients with pneumonia. Ann. $\vec{\circ}$ intern. Med., 72, 183-187.

Heffron, R. (1939). Pneumonia with special reference to $\overrightarrow{\vec{\omega}}$ pneumococcus lobar pneumonia. Commonwealth Fund, New York.

Johanson, W. G., Jr., Pierce, A. K., Sanford, J. P., and Thomas, G. D. (1972). Nosocomial respiratory infections N with gram-negative bacilli. Ann. intern. Med., 77, 701.

Kenny, G. E., Wentworth, B. B., Beasley, R. P., and Foy, $\vec{\circ}$ H. M. (1972). Correlation of circulating capsular poly- $\infty$ saccharide with bacteremia in pneumococcal pneumonia. Infect. Immunity, 6, 431-437.

Laurenzi, G. A., Potter, R. T., and Kass, E. H. (1961). Bacteriologic flora of the lower respiratory tract. New Engl. J. Med., 265, 1273-1278.

Lees, A. W. and McNaught, W. (1959). Non-tuberculous $\frac{\bigcirc}{0}$ bacterial flora of sputum and of the upper and lower respiratory tract in pulmonary tuberculosis. Lancet, 2 , 으 1115.

Louria, D. B. (1962). Uses of quantitative analyses of bacterial populations in sputum. J. Amer. med. Ass., 18 , ज 1082.

Lund, E. (1963). Polyvalent, diagnostic pneumococcus se⿳⺈. Acta path. microbiol. scand., 59, 533-536.

Lund, E. (1970). Types of pneumococci found in blood, $\bar{\partial}$ spinal fluid and pleural exudate during a period of 150 years (1954-1969). Acta path. microbiol. scand., 78, 333-336. \

MacLeod, C. M. (1952). The pneumococci. In Bacterial and Mycotic Infection of Man, edited by R. J. Dubos, 2nd ed. Philadelphia, Lippincott.

Mulder, J. (1938). Haemophilus influenzae (Pfeiffer) as an ubiquitous cause of common acute and chronic purulent bronchitis. Acta med. scand., 94, 98.

Percival, A. (1973). Treatment of respiratory tract infection:웅 A bacteriologist's viewpoint. In Current Antibiotic Therapy? edited by A. M. Geddes and J. D. Williams. Churchill Livingstone, London.

Percival, A. and Roberts, C. (1972). Significance of entero-尺े bacteria and Pseudomonas in sputum. In Microbiology of the Seventies, edited by F. J. Baker, p. 154-165.응 Butterworths, London.

Spencer, R. C. and Philp, J. R. (1973). Effect of previous $D$ antimicrobial therapy on bacteriological findings in으․ patients with primary pneumonia. Lancet, 2, 349-350.

Spencer, R. C. and Savage, M. A. (1974). Pneumococcalo antigen in sputum. Lancet, $1,988$.

Tugwell, P. and Greenwood, B. M. (1974). Bacteriologica $N$ findings in pneumonia. Lancet, 1, 95.

Tugwell, P. and Greenwood, B. M. (1975). Pneumococcal antigen in lobar pneumonia. J. clin. Path., 28, 118-123.

Verhoef, J. and Jones, D. M. (1974). Pneumococcal antigen in sputum. Lancet, 1, 879. 